\title{
Effect of Rainfall and Temperature on Crop Production in Quarit District
}

\author{
Abdi Yirdew*, Yimenu Yeshiwas \\ Department of Physics, College of Natural and Computational Science, Debark University, Debark, Ethiopia \\ Email address: \\ abdiyado0405@gmail.com (A. Yirdaw),yimenuyeshiwas21@gmail.com (Y. Yeshiwas) \\ ${ }^{*}$ Corresponding author
}

\section{To cite this article:}

Abdi Yirdew, Yimenu Yeshiwas. Effect of Rainfall and Temperature on Crop Production in Quarit District. International Journal of Environmental Monitoring and Analysis. Vol. 8, No. 4, 2020, pp. 88-95. doi: 10.11648/j.ijema.20200804.12

Received: February 19, 2020; Accepted: March 12, 2020; Published: August 27, 2020

\begin{abstract}
In this research, we have investigated the effects of rainfall and temperature variability on wheat, Teff, Maize and Barley yield in Quarit district of West Gojjam zone. The data used in this study were temperature, rainfall and (Wheat, teff, maize and barley) yield for the period 1997 to 2016 and Origin 07 and Matlab software were used for the analyses purpose. The weather parameters were correlated with selected crop yield (descriptive and inferential analysis techniques were used). Trend of crop yield and climatic parameters were developed and plotted against time. From this study, there was positive correlation between maximum temperature and all selected crop production (Maize, teff, wheat and barley) and there was correlation between these selected crop yields and rainfall. There has been variability and none stability of temperature and rainfall in the study area, leads to high variability of crop yields from year to year in the study area. This finding has demonstrated that, there was an increasing trend of temperature and very slightly decreasing trend of rainfall in Quarit district. Teff production was the most sensitive and affected by climate variability. Results showed that crop yield varied regularly with climate parameters. It was concluded that climate parameters (temperature and rainfall) vary in time whose effects given high variability of crop yield.
\end{abstract}

Keywords: Rainfall, Temperature Variability, Wheat, Teff, Maize ana Barley, Yield, Ethiopia

\section{Introduction}

Atmosphere is the blanket of air which composed of both permanent and variable gases that surrounds the earth, moving both vertically and horizontally causing variation in climate and weather events like temperature, humidity, atmospheric pressure, wind, precipitation, ultraviolet light, and other climate variables that occur over long periods of time and change and variability of earth's climate is due to the change of those the variable gases like carbon dioxide, methane, ozone and water vapour. Recently, studies have realized that greenhouse gases such as carbon dioxide, water vapour, ozone, and methane lead to changes in climate conditions such as temperature, precipitation, soil moisture, humidity, atmospheric pressure and sea levels giving adverse effects on ecological systems, agriculture, human health, and the economy and the intergovernmental Panel on Climate Change forecasts that during this century, there will be an increase in the average global surface temperatures by $2.8^{\circ} \mathrm{C}$, estimates of the increase ranging from 1.8 to $4.0^{\circ} \mathrm{C}$. It is thought that these increases will be brought about by the increase in the atmospheric concentration of greenhouse gases. As a result, the natural system would be altered in many ways: the frequency of extreme weather events would increase, sea levels would rise, ocean currents would reverse, and precipitation patterns would change and these changes could bring about serious long-term social and economic consequences. Specifically, the potential of agricultural production and human health will be substantially affected by the predicted changes in temperature and rainfall patterns [1].

In Ethiopia, meteorological data recorded over the past 55 years indicated that there has been a warming trend in the annual minimum temperature and was increasing at a rate of about $0.37^{\circ} \mathrm{C}$ per decade. The trend of the country's average annual rainfall on the other hand has remained more or less constant. Thus, the country is in particular highly vulnerable to drought and floods, heavy rains, strong winds, frost, heat waves, lightning etc causing food insecurity, land 
degradation and infrastructural damage and outbreak of diseases like malaria, allergies and asthma [2]. It is apparent that crop yield primarily depends on weather conditions, diseases and pests, planning of harvest operation etc of the region. Thus, effective management of these factors is important. Annual as well as seasonal crop yield variations in Ethiopia can be partly explained by rainfall patterns and temperature. According to Agricultural economists, rainfall variability greater than $30 \%$ is risky for farmers who depend on yearly income of crop production [3]. Identified that, in Ethiopia climate change reduced yield of wheat staple by $33 \%$ [4].

Thus, Amhara region, which taken second in crop production in Ethiopia next to the Oromia regional state [5] is affected much from climate change and variability. There has been no single year with no drought in the eastern part of the region since 1950 [6]. Similarly, a study of Ethiopian farmers' vulnerability to climate change across seven regional states [7], made clear that, the Amhara region has suffered by droughts and floods. The study has identified $70 \%$ of households in 8 districts in West Gojjam zone have food security problem [8]. It has been analyzed that West gojjam zone temperature, especially minimum temperature, is warming at a rate faster than the national average, implying increasing evapo-transpiration and hence further water shortage in the region [9].

The agriculture-climate change and variability connection has already become a research theme from global to regional or local levels. The research so far effort especially at the global level, this is especially a challenge with subsistence agriculture since predicting the influence of climate change on subsistence farmer households at international level is a very difficult task due to standard definitions, lack of bench mark data, its location specificity, variations in the households' [10].
However, this study had been tried to analyze the effect of climate variables (temperature and rainfall) on crops at regional level because, analysis of such climatic variables at regional level is better than the global one as it is easy to identify the problem regarding to the change and variability of climate parameters in the area of study. Specifically, this study was aimed to analyze the influence of long term inter annual variability of rainfall and temperature on crops in the selected area of West Gojjam zone, Amhara, Ethiopia by using inferential (multiple regression and correlation analysis) and descriptive statistical (standard deviation, standard anomalies mean and variance) techniques.

\section{Data Sources and Methodology}

\subsection{Description of Study Area}

The Ethiopia's economy is based on the agricultural sector because of its contribution to the total income of the country and this study aims to assess the effect of rainfall and temperature variability's on the yield of major food crops (Wheat Maize, Teff, and Barley) grown in most part of West Gojjam of Amara region of Ethiopia country. In fact, that the country is extremely vulnerable to climate change and variability due to its geographical location, high population and low technological resource. This study was conducted in Quarit district, West Gojjam zone of the Amhara regional state. The Amhara region is located in the north and northwestern part of Ethiopia between latitudes of $9^{\circ} 20^{\prime}$ and $14^{\circ}$ $20^{\prime}$ North and $36^{\circ} 20^{\prime}$ and $40^{\circ} 20^{\prime}$ East longitudes. West Gojjam zone is located in the south-western part of the Amhara region. West Gojjam zone, which is located in the direction at $385 \mathrm{~km}$ from Addis Ababa, has a total population of 2,474,254 (1,220,477 males and 1,253,777 females [11].

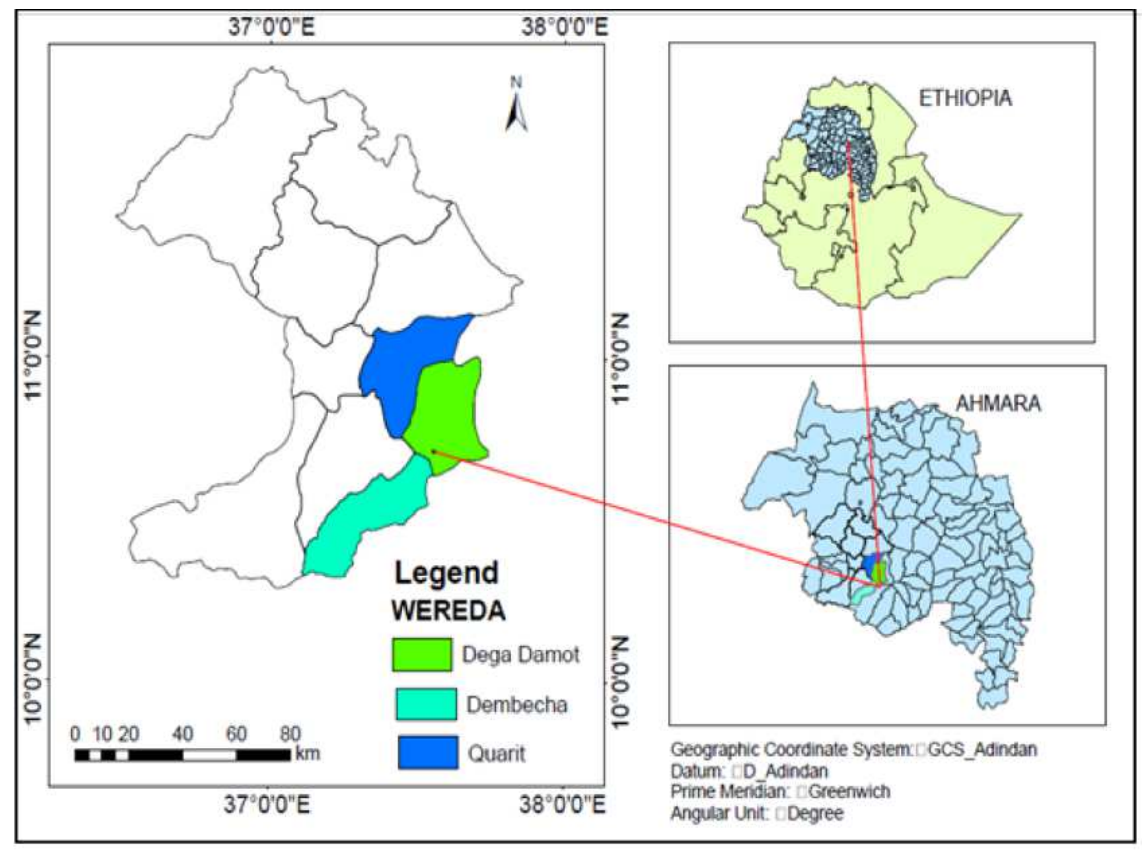

Figure 1. Location map of the study area. 
The mean annual temperature of the region ranges from $22-27^{\circ} \mathrm{C}$ in the lowlands and between 10 and $22^{\circ} \mathrm{C}$ in the highlands up to 3,000 meters above sea level [12]. The long term mean annual rainfall of the region is $1165.2 \mathrm{~mm}$. However, areas in the specific study sites received 1100 to $1360 \mathrm{~mm}$ of mean annual rainfall per year [13].

\subsection{Data Source}

This study aims to assess the effect of climate variables (mean annual rainfall and mean annual maximum temperature and minimum temperature) variability on the yield of major food crops (Wheat, maize, teff and barley) grown in most part of West Gojjam of Amhara region of Ethiopia country. This study depends on secondary data covering period of 1997 to 2016 years.

The data for study was collected from Amhara, Ethiopia metrological data station in the capital city of Amhara region in the Bahirdar city and districts'- wise yearly data on the yield of the reported crop collected from Agricultural development project bureau of west Gojjam Amhara region, Ethiopia in Fenotaselam capital city of West Gojjam zone.

\subsection{Methods}

The meteorological time series data collected include; annual rainfall, annual minimum and maximum temperature over covering period of 1997 to 2016 years. Similarly, the time series agronomic data was collected from Amhara region Agricultural development project bureau of West Gojjam zone includes; district-wise yearly output yields of major crops such as; Maize, teff, wheat and barley from 1997 to 2016 years. In this study, descriptive statistics, multiple regression, coefficient of variation (CV), standard rainfall and Temperature anomalies and correlation analysis were used to analyze the findings. The mean of ten-year crop yields separately has calculated to evaluate the ten-year difference in crop yields in study area due to the effect annual rainfall and annual maximum and minimum temperature over 1997 to 2016.

The appropriate annual rainfall and annual temperature (maximum and minimum) were captured into Matlab software 2013 and Origin 7 software. The spread sheet followed the series of the year from 1997 to 2016 entry format.

In order to study yearly variability of rainfall, temperature and crop production in the study area, the coefficient of variation $(\mathrm{CV})$ has calculated as the ratio of standard deviation to the mean[14]. This described as expressed in equation (1).

Percent Coefficient of Variation (CV\%)

$$
\mathrm{CV}=\delta / M^{*} 100 \%
$$

Where $\delta$ and $\mathrm{M}$ are standard deviation and mean annual rainfall respectively over the period of observations. CV (\%) values are classified as follows: $<20 \%$ as less variable, 20 $30 \%$ as moderately variable, and $>30 \%$ as highly variable [14]. On the other hand, standard deviation is computed as the square root of variance. Using the classification of Reddy (1990), the stability of rainfall is examined as follows: when standard deviation $<10$ as very high stabilities, 10-20 as high stability, and $20-40$ as moderate stability and $>40$ as less stability [15]. Where Standard Deviation (SD) can be computed as expressed in Equation (2).

$$
\mathrm{SD}=\sqrt{\sum_{i=1}^{n} \frac{\left(X_{i}-X_{m}\right)^{2}}{n}}
$$

Where $\mathrm{Xi}, \mathrm{Xm}$ and $\mathrm{n}$ are each year value of parameters rainfall, the mean value over observation and number of year of observation.

The standard rainfall anomalies (SRA) were calculated and graphically represented to evaluate inter annual fluctuation of rainfall and temperature in study area as described in equation (3).

$$
\mathrm{SRA}=\frac{\left(R_{t}-R_{m}\right)}{\delta}
$$

$R_{t}$, is annual rainfall at time $\mathrm{t}$ and $R_{m}$ is long term mean annual rainfall over period of observation in this study and $\delta$ is the standard deviation of the observation. Based on SRA values, these statistics are enable us to determine the dry (-ve values) and wet (+ve values) years over study period from 1997 to 2016 years. To investigate the nature of the trends in the rainfall and temperature series, linear trend lines were also plotted for annual rainfall, annual temperature (maximum and minimum) and crop production using Mat Lab Software (2013).

Correlation and multiple linear regression methods were used to establish the relationship, cause and effect of rainfall and temperature characteristics on wheat, barley, maize and teff yields.

Coefficients of multiple determinations $\left(R^{2}\right)$ were used to determine the percentage of variation explained jointly by the rainfall and temperature characteristics.

Correlation analysis was carried out to determine the relationship that exists between wheat yield and each of the climatic parameters. The following correlation coefficient formula was used to obtain the correlation coefficients. it is governed by equation (4).

$$
R_{x y}=\frac{\frac{1}{n} \sum_{i=1}^{n}[(X-(X)) *(Y-(Y))]}{\left[\frac{1}{n} \sum_{i=1}^{n} \frac{(X-\hat{X})^{2} * 1}{n} \sum_{i=1}^{n}(Y-\dot{Y})^{2}\right]^{\frac{1}{2}}}
$$

Where, $\mathrm{X}$ is yield, $\mathrm{Y}$ is climatic variables value, $X$ is the mean values of yield, $Y$ is the mean values of climatic variables data value and $\mathrm{n}$ is the number of observation. Pearson Correlation coefficient $\left(R_{x y}\right)$ analyses were used to analyze the correlation between crop yields with rainfall and temperature characteristics. The values of $R_{x y}$, ranges between -1 to +1 . Correlation coefficient closes to +1 indicates a strong positive correlation, a correlation coefficient closes to -1 indicates a strong negative correlation similarly a correlation coefficient of 0 indicates no correlation and the associated p-value indicates, the significance probability of the correlation $R_{x y}$ to be zero.

\section{Result and Discussions}

Long term variation of annual rainfall and (maximum and 
minimum) temperature and maize, teff, wheat and barley in Quarit district.

\subsection{Trends and Variability Analysis in Quarit District}

For this analysis, rainfall, temperature and crop yield data
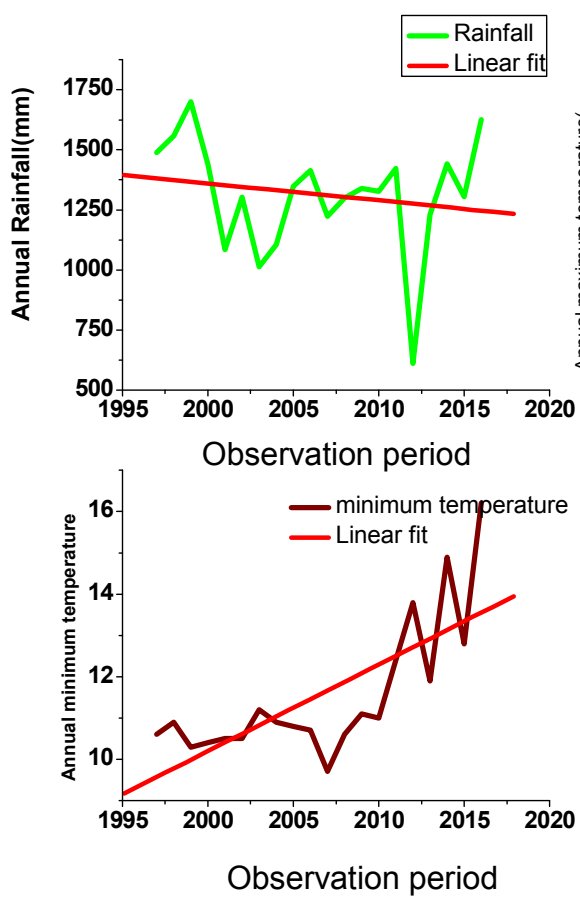

from 1997 to 2016 years have been used and interpreted by graphs as follow. To analysis the trends of each variables, the data has been fitted linearly by using origin 07 and mat lab 2013 software.

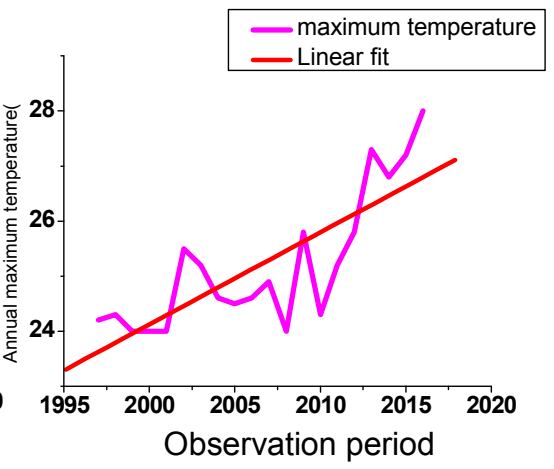

Figure 2. Annual rainfalls, Annual mean maximum temperature and annual mean minimum temperature against time graph and trend in Quarit district.

Figure 2 demonstrate that slightly decreasing trends of annual rainfall over the study period. From farther analysis, the annual rainfall of Quarit was decreased by $62.64 \mathrm{~mm}$ per decade and by 6.3 per year in this time of observation from 1997 to 2016. Whereas, there has been strictly increasing trends of annual maximum temperature and annual minimum temperature over the study period.

From farther analysis, the annual maximum temperature and annual minimum temperature of Quarit were increased by $1.4^{\circ} \mathrm{c}$ per decade and $1.76^{\circ} \mathrm{c}$ per decade and 0.14 per year and 0.18 per year respectively in this time of observation from 1997 to 2016 in the study area.
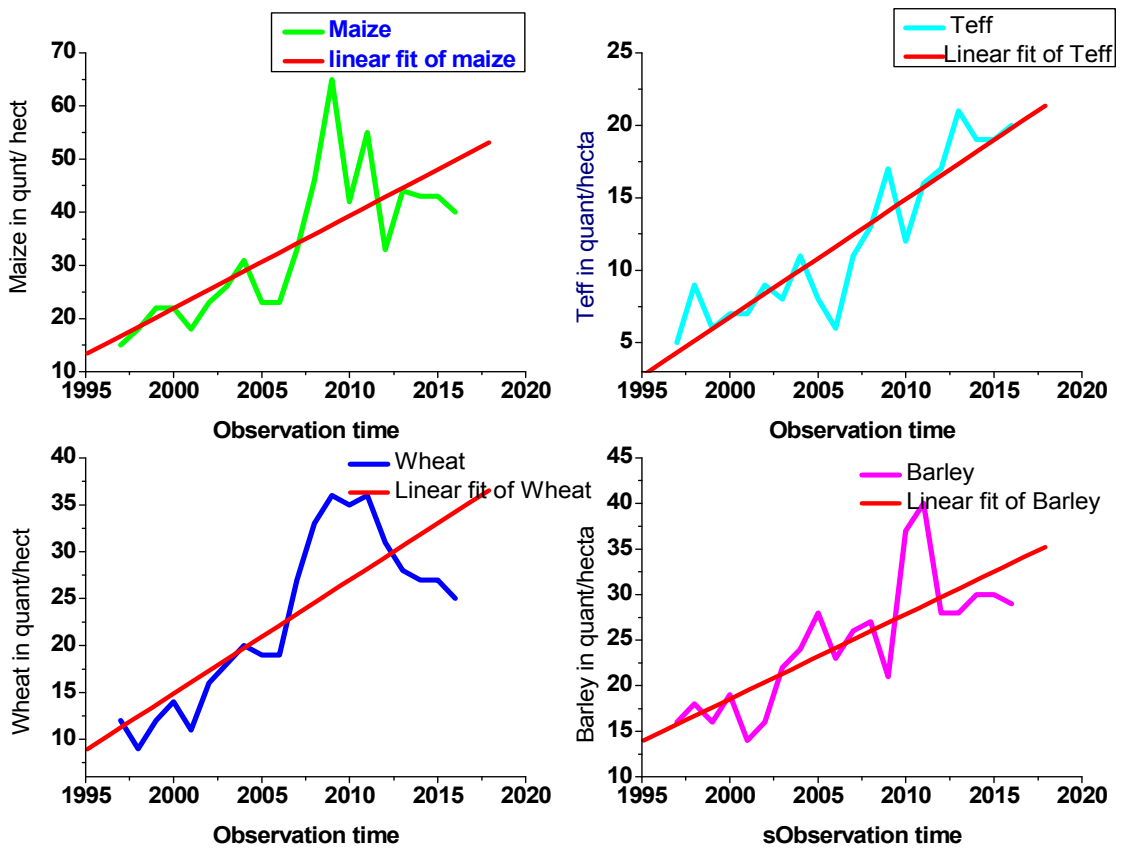

Figure 3. Maize, Teff, Wheat and Barley yields in quintals per hectare against time graph and trend in Quarit district. 
Figure 3 indicate that the trend of cereal crop production in the Quarit district, as seen from the crop data, maximum amount of crop yields like Maize, Teff, Wheat and Barley over the study period were $65 \mathrm{qun} / \mathrm{hec}$ in the year of 2009,20 qun/hec in the year of 2016, 36 qun/hec in the year of $(2011$ and 2011) and 40 qun/hec in the year of 2011 respectively. The minimum amount of crop yields was Maize 15 qun/hec in the year 1997, Teff 5 qun/hec in the year 1997, Wheat 9 qun/hec in the year 1998 and Barley 14 qun/hec in the year of 2011, this result shows that, there was an increasing trend of all crops yield over the study period, but yield have been varying annually. This is due to varying climatic parameters over the study period from 1997 to 2016 in the study area.

\subsection{Statistical Analysis of Long Term Variation of Annual Rainfall and (Maximum and Minimum) Temperature and Crop Yield in Quarit District}

This method of analysis includes descriptive statistical and inferential statistical analysis method that presented in the above research method analysis section. Therefore, coefficient of variation (equation 1), mean, standard deviation (equation 2), standard rainfall anomalies (SRA) equation (3) and correlation coefficient (equation 4) and regression (coefficient of determination) were used for the purpose of analyzing variability, stability, relation of climatic variables and crops yield and percentage variability of crops yield caused by climatic variables in the study area. Thus, the results have interpreted as the following in the tables.

\subsubsection{Descriptive Statistical Analysis}

This result has interpreted by using descriptive statistical analysis method given in the method of analysis section of this research. Thus, equation (1) and (2) were used to analysis the variability and stability of selected climatic parameters and crops yield data covering year observation period from 1997 to 2016 .

Table 1. Descriptive statistics of annual rainfall, annual temperature and maize, teff, wheat and barley yield over Quarit district during 1997 up to 2016.

\begin{tabular}{|c|c|c|c|c|c|}
\hline Variables & Maximum & Minimum & Mean & Standard deviation & Coefficient of variation (CV\%) \\
\hline Annual rainfall (mm) & 1701 & 611.3 & 1314 & 239.4 & $18.2 \%$ \\
\hline Annual maximum temperature $\left({ }^{\circ} \mathrm{C}\right)$ & 28 & 24 & 25.21 & 1.242 & $4.9 \%$ \\
\hline Annual minimum temperature $\left({ }^{\circ} \mathrm{C}\right)$ & 16.2 & 9.7 & 11.56 & 1.676 & $14.5 \%$ \\
\hline Maize yield & 65 & 15 & 33.25 & 13.562 & $40.78 \%$ \\
\hline Teff yield & 21 & 5 & 12.05 & 5.29 & $43.9 \%$ \\
\hline Wheat yield & 36 & 9 & 22.75 & 8.88 & $39 \%$ \\
\hline Barley yield & 40 & 14 & 24.6 & 7.04 & $28.62 \%$ \\
\hline
\end{tabular}

Table 1 shows maximum amount of annual rainfall $(1701 \mathrm{~mm})$, annual maximum temperature $\left(28^{\circ} \mathrm{C}\right)$, annual minimum temperature $\left(16.2^{\circ} \mathrm{C}\right)$, Maize yields $(65$ qun $/$ hect $)$, Teff yields (21qunt/hect), Wheat yields (36 qun/hect) and Barley yields (40 qun/hect) seen in the year of 1999, 2016, 2016, 2009), 2013, 2011 and 2011 respectively and minimum amount of annual rainfall $(611.3 \mathrm{~mm})$, annual maximum temperature $\left(24^{\circ} \mathrm{C}\right)$, annual minimum temperature $\left(9.7^{\circ} \mathrm{C}\right)$, Maize yields (15qunt/hect), Teff yields (5 qunt/hect), Wheat yields (9 qunt/hect) and Barley yields (14 qunt/hect) is seen in the year of 2012, (1999, 2000,2001 and 2008), 2007, 1997, 1997, 1998 and 2001 respectively. This result demonstrates that, maximum amount of crop yields (Maize, Teff, Wheat and Barley) are mostly recorded with maximum amount of the maximum annual temperature, therefore, Maize, Teff, Wheat and Barley production is increased with an increase in the annual maximum temperature.

Coefficient of variability of annual rainfall, annual maximum temperature and annual minimum temperature is $18.2 \%, 4.9 \%$ and $14.5 \%$ respectively. According to Hare (1983), CV (\%) values are classified as follows: $<20 \%$ as less variable, $20-30 \%$ as moderately variable, and $>30 \%$ as highly variable. Thus, from the results, it indicates less variability of annual rainfall and annual temperature and standard deviation demonstrated that none stability of rainfall and temperature patterns in Quarit district.

Coefficient of variability of Maize, Teff, Wheat and Barley is $40.78 \%, 43.9 \%, 39 \%$ and $28.62 \%$ respectively. This result shows, high variability in crop production in the study area and maize and Teff yields are the most variable one, therefore, maize and Teff yields were the most affected by climate variability in the study area and in general, less variability in annual rainfall and annual temperature may cause high variability in crop production.

\subsubsection{Inferential Statistical Analysis}

Pearson correlation coefficient and coefficient of determination has been used to analysis the relation between selected crops and climatic parameters, and percentage of crop production affected by climatic variables and the result has processed by using equation (5) presented in the research method section.

Table 2. Regression Analysis for crops and Annual rainfall in Quarit district.

\begin{tabular}{llll}
\hline CROP & $\mathbf{R}$ & $\boldsymbol{R}^{\mathbf{2}}$ & P value of annual rainfall \\
\hline Maize & -0.032 & 0.001 & 0.89 \\
Teff & -0.138 & 0.02 & 0.56 \\
Wheat & -0.24 & 0.06 & 0.30 \\
Barley & -0.087 & 0.008 & 0.71 \\
\hline
\end{tabular}

Table 2, represents the regression analysis between annual rainfall and crop production like Maize, Teff, Wheat and Barley in Quarit district. It shows that the coefficient of determination of Maize (0.001), Teff (0.02), Wheat (0.06) and Barley (0.008) with the probability of correlation coefficient $\mathrm{R}$ to zero for Maize (0.89), Teff $(0.56)$, Wheat (0.30) and Barley (0.71). This results show that the percentage variability of Maize $(0.1 \%)$, Teff $(2 \%)$, Wheat 
(6\%) and Barley $(0.8 \%)$ was due to annual rainfall in Quarit district and $\mathrm{P}$ value of crop production indicate that there was high probability of getting $\mathrm{R}$ zero. From this regression analysis crop production was less affected by annual rainfall and there was no strong relation between annual rainfall and crop production like Maize, Teff, Wheat and Barley in Quarit district, therefore, crop production was affected due to other factor those determining the yield of crop.

Table 3. Regression Analysis for crops and Annual maximum temperature in Quarit district.

\begin{tabular}{llrl}
\hline CROP temperature & $\mathbf{R}$ & $\boldsymbol{R}^{\mathbf{2}}$ & P value of Annual maximum \\
\hline Maize & 0.5 & 0.25 & 0.024 \\
Teff & 0.85 & 0.72 & 0.0001 \\
Wheat & 0.4 & 0.16 & 0.072 \\
Barley & 0.4 & 0.16 & 0.088 \\
\hline
\end{tabular}

Table 3, represents the regression analysis between annual maximum temperature and crop production like Maize, Teff, Wheat and Barley in Quarit district.

It shows that, the coefficient of determination of Maize (0.25), Teff (0.72), Wheat (0.16) and Barley (0.16) with the probability of correlation coefficient $\mathrm{R}$ to zero for Maize (0.024), Teff (0.0001), Wheat (0.072) and Barley (0.088). This result show that the percentage variability of Maize $(25 \%)$, Teff (72\%), Wheat (16\%) and Barley (16\%) was due to annual maximum temperature in Quarit district.

$\mathrm{P}$ value of crop production indicates that, there was less probability of getting $\mathrm{R}$ zero. From this regression analysis crop production was affected by annual maximum temperature and there was strong relation between annual maximum temperature and crop production like Maize, Teff, Wheat and Barley in Quarit district. However, from this analysis Teff production was the most affected by annual maximum temperature than the other and annual maximum temperature was significant for Maize, Wheat and Barley in Quarit district, therefore, farmers should cultivate those adapting maximum temperature.

Table 4. Regression Analysis for crops and Annual minimum temperature in Quarit district.

\begin{tabular}{llcl}
\hline CROP & $\mathbf{R}$ & $\boldsymbol{R}^{\mathbf{2}}$ & P value of Annual minimum temperature \\
\hline Maize & 0.39 & 0.15 & 0.089 \\
Teff & 0.74 & 0.55 & 0.00015 \\
Wheat & 0.36 & 0.13 & 0.115 \\
Barley & 0.5 & 0.25 & 0.033 \\
\hline
\end{tabular}

From the table, it demonstrates that regression analysis between crop production and annual minimum temperature in Quarit district. It represents that the coefficient of determination of Maize, Teff, Wheat and Barley are 0.15, 0.55, 0.13 and 0.25 respectively with $\mathrm{P}$ value of $0.089,0.00015$, 0.115 and 0.033 respectively. This result shows that $15 \%, 55 \%$, $13 \%$ and $25 \%$ variability of Maize, Teff, Wheat and Barley yield due to annual minimum temperature and the other percent is not due to annual minimum temperature and the probability of R to be zero is very less indicating that there was strong relation between crop production and annual minimum temperature. Thus, crop production was affected by variability of annual minimum temperature in Quarit district.

From regression analysis Teff is the most affected by annual minimum temperature than the other. Therefore, Teff production is the most sensitive to temperature variability in Quarit district.

Table 5. Correlation analysis in Quarit district.

\begin{tabular}{llll}
\hline $\begin{array}{l}\text { Types of } \\
\text { crop }\end{array}$ & $\begin{array}{l}\text { Annual } \\
\text { rainfall }\end{array}$ & $\begin{array}{l}\text { annual minimum } \\
\text { temperature }\end{array}$ & $\begin{array}{l}\text { annual maximum } \\
\text { temperature }\end{array}$ \\
\hline Maize & $-0.032 * *$ & $0.39 * *$ & 0.5 \\
Teff & $-0.138^{*}$ & 0.74 & 0.85 \\
Wheat & -0.24 & 0.36 & $0.4 * * *$ \\
Barley & $-0.087 * *$ & 0.5 & $0.4 * * *$ \\
\hline
\end{tabular}

Significant at $0.5(*)$, significant at $0.8(* *)$, significant at $0.6(* * *)$, significant at 0.5

As presented in table 5, it indicates that the correlation value of annual maximum temperature and minimum temperature against all selected crop yield are positive, it indicates an increase or decrease in minimum and maximum temperature lead to the same result an increase or decrease in yield of these selected crops and annual rainfall is negatively correlated with all selected crop yield, in this study area.

Implying that increasing or decrease of rainfall leads the contradicting effect (decrease or increase) on the yield of those selected crop (Maize, Teff, Wheat and Barley) in Quarit district.

The correlation value of annual maximum temperature and annual minimum temperature against all selected crop yield are positive, whereas, annual rainfall is negatively correlated with the entire selected crop yield in this study area. Therefore, the yield of Maize, Teff, Wheat and Barley were increasing with temperature, however, the amount of crop yields were not adequate this may be due to decreasing in rainfall in the study area. Moreover, decrease in rainfall and an increase in temperature may lead drought and infrastructural damage in this area of study in the future.

\subsubsection{Standard Rainfall Anomalies (Fluctuation from Mean Value per Standard Deviation) Against Time Graph}

The purpose of this analysis was for determination of dry and wet years passed in the study area during the time of observation from 1996 to 2016. For this analysis, standard rainfall anomalies equation (3) in the method of analysis was used and the result has been interpreted in the figure 4 bellow. From this result, negative anomalies indicate dry year and positive anomalies indicates wet year during study times.

Figure 4 indicates, projected Year to year variation of annual rainfall for Quarit and it is expressed in terms of normalized rainfall anomaly. As it can be depicted in the figure, Quarit and the surrounding region is expected to experience both unusual wet and dry years than the climatologically conditions year between 1997 and 2016 and highest negative anomalies occurred in 2002 (-1.5) and in 2012 (-3) these are dry year in Quarit district. From the trend lines of the annual rainfall, there will be a clear indication of a slight decrease in rainfall trend. 
The finding revealed that annual rainfall amount decreased by about $62.64 \mathrm{~mm}$ per decade and by 6.3 per year in study period.

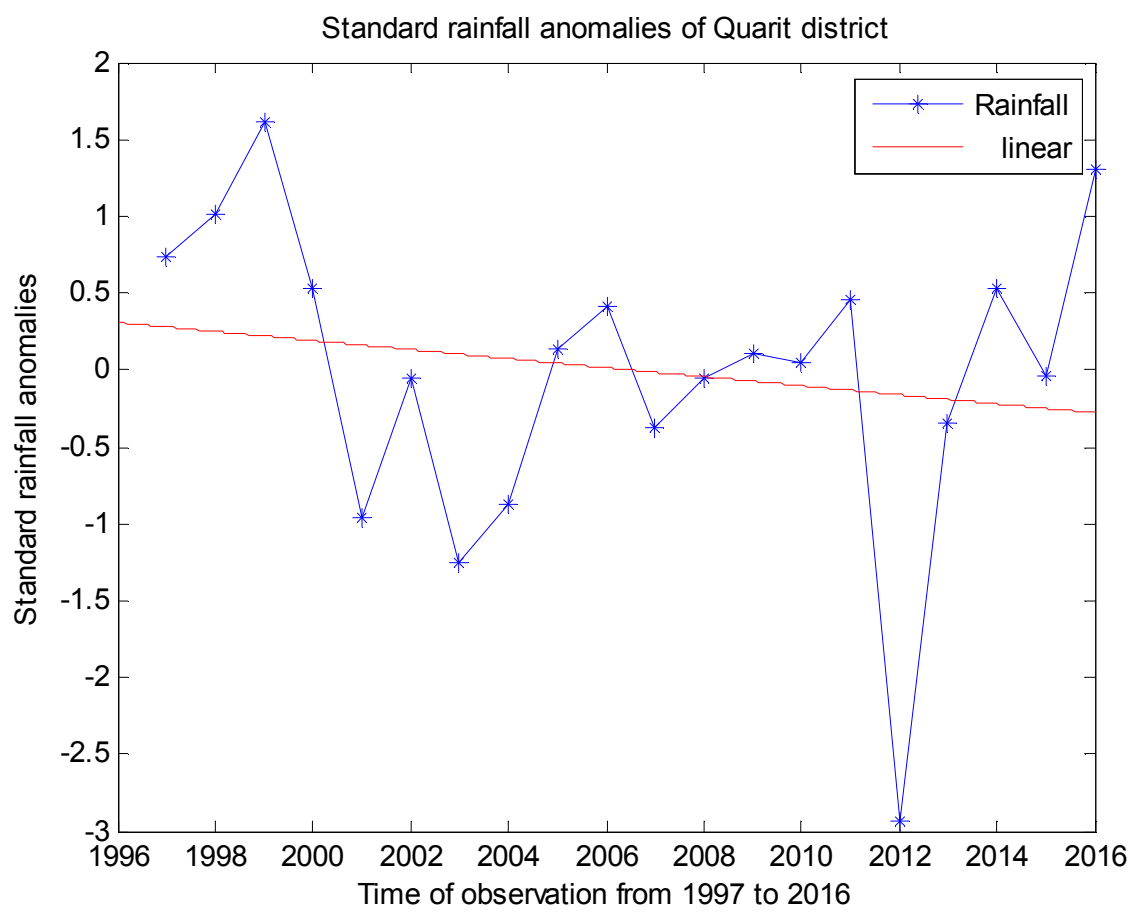

Figure 4. Standard rainfall anomalies in Quarit district.

\section{Conclusion}

From this study, there was positive correlation between maximum temperature and all selected crop production (Maize, Teff, Wheat and Barley). Whereas, there was negative correlation between these selected crop yields and rainfall in Quarit district and coefficient of determination shows, crop yield was affected by the variability of annual maximum and minimum temperature in Quarit district. The result shows, there has been variability and no stability of Temperature and rainfall. Thus, it leads to high variability of crop yields from year to year in the study area.

This finding has demonstrated that, there was an increasing trend of temperature and very slightly decreasing trend of rainfall in Quarit district. Moreover, there was variability of temperature and rainfall from year to year that lead to high variability of crop yield over the study period.

In these study area, Teff production was the most sensitive and affected by climate variability than maize, Wheat and Barley. Although the affect was more for Teff, all crop yields were affected by the variability of temperature in the study area. In Ethiopia, meteorological data recorded over the past 55 years indicated that there has been a warming trend in the annual minimum temperature and was increasing at a rate of about $0.37^{\circ} \mathrm{C}$ per decade and the trend of country's average annual rainfall has remained more or less constant and it is characterized by a high degree of spatial and temporal variability[2].

However, this finding has analyzed that the annual minimum temperature has been increased by $1.4^{\circ} \mathrm{C}$ per decade in Quarit. This indicates highly increasing temperature in the study area than the meteorological data recorded over past 55 years and annual rainfall has decreased by $62.6 \mathrm{~mm}$ per decade in Quarit district. This will may take the study area under food insecurity, infrastructural damage, water shortage and health problem So that, climatologist should emphasize to give forecasting mechanism and agronomist should inform adaptation strategies for the farmers of study area. Moreover, the government must give emphasize on about the climate of the country since life is in the climate. In fact, there is burning of forest frequently for unknown reason in different area in Ethiopian, this may lead our country's climate condition to be unstable and change. Thus, such activity should be emphasized to stop by the government of the country because its effect can distribute to the whole regions and it may lead to uncontrollable climate change risk in the country.

\section{References}

[1] IPCC (Intergovernmental panel on Climate Change), (2007), "Climate change; the scientific basis".

[2] National Meteorological Agency, (2007), Climate Change National Adaptation Program of Action (NAPA) of Ethiopia, Addis Ababa, Ethiopia.

[3] Roarane, A. A. and Kulkari, R. V., (2012), "Data Mining: An Effective Tool for Yield Estimation in the Agricultural Sector", Report of the Intergovernmental Panel on Climate change Cambridge: Cambridge University press.

[4] World Bank, (2006), "The Economics of Adaptation to Climate Change, the World Bank Group". 
[5] Central statistical agency (CSA), (2011), Addis Ababa, Central Ethiopia, CD-ROM.

[6] United States Agency for International Development (USAID), (2000), Amhara National Regional State Food Security Research Assessment Report, Unpublished research Report, USAID-Ethiopia, Addis Ababa.

[7] Deressa T, R. M. Hasan, and C. Ringer, (2008), "Measuring vulnerability of Ethiopian farmers to climate change across regional state", IFPRI Discussion paper No. 806, Washington $D C$.

[8] Amhara Regional State Food Security Coordination and Disaster Prevention Office (AFSCDPO), (2007), an assessment of the condition of food security in nine woredas of western Amhara. A report submitted to the Regional disaster prevention and preparedness committee, Bahirdar, unpublished.

[9] Berhanu Eskezia, (2015), "Farmers' Vulnerability and Response strategies to Climate Change and variability over Amhara Region, Ethiopia”.

[10] Morton J. F., (2007) "The impact of climate change on small holder and subsistence agriculture", Proceedings of the Dational Academy of Science, 104 (50).

[11] Amhara Bureau of Finance and Economic Development, (2014), Population Size by Sex and Age Group and Urban and Rural.

[12] Amhara National Regional States (ANRS), (2002), A Strategic plan for the Sustainable Development, Conservation, and Man agreement of the woody Biomass Resources, Final Report.

[13] Ayalew D, Tesfaye K, Mamo G, Yitaferu B. and Bayu W., (2012) Variability of rainfall and its current trend in Amhara Region, Ethiopia. African Journal of agricultural Research Vol. 7 (10): 1475-1486.

[14] National Meteorological Services Agency (NMSA), (1996), "Climatic and agro-climatic resources of Ethiopia". Metrological Research Report Series, 1:1, January. Addis Ababa, Ethiopia.

[15] Reddy S. J., (1990), “Meteorology: Agro-climatic Analogue Technique and Applications as relevant to Dry Land Agriculture". Agro-climatologicallySeries Eth 86/021WMO/UNDP/NMSA, Addis Ababa, Ethiopia. P60. 